\title{
Heart failure - the experience of living with end-stage heart failure and accessing care across settings
}

\author{
Rosemary Chester $^{1}$, Heather Richardson ${ }^{2}$, Christopher Doyle $^{2}$, Fiona Hodson ${ }^{2}$, Joy R. Ross ${ }^{2}$ \\ ${ }^{1}$ Department of Palliative Medicine, Pilgrims Hospice, Canterbury, Kent, UK; ${ }^{2}$ Department of Palliative Medicine, St. Christopher's Hospice, \\ London, UK \\ Contributions: (I) Conception and design: H Richardson, F Hodson, JR Ross; (II) Administrative support: All authors; (III) Provision of study materials \\ or patients: F Hodson, JR Ross; (IV) Collection and assembly of data: R Chester, C Doyle, F Hodson, JR Ross; (V) Data analysis and interpretation: \\ All authors; (VI) Manuscript writing: All authors; (VII) Final approval of manuscript: All authors. \\ Correspondence to: Rosemary Chester, BMBS, MRCP(UK), PGDip.Pall.Med. ST6 Specialty Training Registrar in Palliative Medicine, Pilgrims \\ Hospice Canterbury, 56 London Road, Canterbury, Kent, CT2 8JA, UK. Email: rosemary.chester@nhs.net.
}

Background Heart failure is a complex clinical syndrome affecting an increasing number of the ageing population. Patients and carers require increasing input from specialist palliative care services to both manage symptoms and access support in the last year of life. An integrated clinical service between the local cardiology team at Princess Royal University Hospital and the palliative care team at St. Christopher's Hospice was piloted for patients with end-stage heart failure in Bromley in Kent, UK. This study explored views of patients and carers who participated in the integrated pilot service.

Methods: A qualitative study was conducted in which a convenience sample of patients and carers were invited to participate in focus groups: two bereaved carer groups $(n=2, n=2)$; one patient group ( $n=4)$, held between 14th December 2018 and 18th January 2019. Participants were asked to describe their experiences of care received facilitated by a topic guide. Interviews were recorded, transcribed and coded using thematic analysis to identify common themes.

Results: Four patients (2:2 M:F) aged between 70 to 87 years and four female carers whom had cared for patients aged between 70 to 96 years who were since deceased, participated in this study. Overall, the service was positively received, and responses were mapped into four key areas; being diagnosed and living with heart failure, referral to palliative care, key helpful components of the care received and finally, unhelpful components of the new service in terms of care. Common themes emerged including understanding of heart failure and its trajectory, communication around palliative care, having a 'broker' for the system, recognition of carer's needs, service responsiveness, and feeling 'in control'.

Conclusions: This qualitative study highlighted important considerations when developing an integrated heart failure and palliative care service. Education about heart failure for patients and carers, but also the integrated multidisciplinary team is crucial to improving detection of deterioration and facilitating communication around Advance Care Planning. The value of the 'expert-carer' should also be promoted and supported in chronic conditions. We recommend a focus on development of integrated services that enable joined-up care or single point of contact for patients and carers.

Koywords: Heart failure; palliative care; integration; carers; quality of life

Submitted Mar 25, 2021. Accepted for publication Jun 09, 2021.

doi: 10.21037/apm-21-709

View this article at: https://dx.doi.org/10.21037/apm-21-709

\footnotetext{
^ ORCID: 0000-0003-3132-0923.
} 


\section{Introduction}

Heart failure is a complex clinical syndrome of symptoms and signs due to impairment in cardiac efficiency caused by structural or functional abnormalities of the heart. It affects around 920,000 people in the UK today, and the incidence and prevalence are increasing as our ageing population continue to live longer (1). It is predominantly a disease of older people, with at least $5 \%$ of those aged over 75 years affected, rising to about $15 \%$ in the very old (2). Palliative care needs for older patients living with frailty and multimorbidity are poorly understood and access to palliative care services is limited (3).

Palliative care has a role to play across the stages of heart failure requiring a multidisciplinary approach to care. This should focus on communication, shared decision making, advance care planning, symptom control, psychological and spiritual care, and offer a support system to help families and carers cope throughout the patient journey and beyond, to care after death $(4,5)$.

Guidelines issued by the European Society of Cardiology $(6,7)$ and the National Institute for Health and Care Excellence (NICE) (1) for the management of heart failure suggest that palliative care should be introduced at an early stage and the input increased throughout the disease trajectory. It has been shown that palliative care input is linked to statistically and clinically significant improvements in patient's quality of life and is also associated with lower utilisation of healthcare resources (8-10). This benefit has also been recognised in patients with frailty and many other comorbidities which often co-exist with end-stage heart failure and increase the complexity and uncertainty of the disease trajectory (11).

A local intervention between cardiology and palliative care, funded by Bromley Clinical Care Commissioning Group (CCG) was developed and piloted between May 2017 to September 2018, taking referrals from six local general practices. Patients that met the referral criteria (anyone with a clinical diagnosis of heart failure, likely to be in last year of life, and referred from the participating general practices, or with complex needs identified by the Princess Royal University Hospital Cardiology Team or Palliative Care Team) were consented and then assessed by an experienced advanced nurse practitioner with both heart failure and palliative care experience. A total of 89 patients were accepted onto the pilot and a range of outcomes were measured including Integrated Palliative Outcome Scale (IPOS), views on care, place of death and use of hospital inpatient beds. This model of care had significant benefits in reducing hospital bed-days and admissions (36\% reduction in admissions, $51 \%$ reduction in hospital beddays, compared with 1 year pre-pilot), increasing patients ability to die outside of hospital [44\% of patients died; $69 \%$ at home or hospice $(41 \% / 28 \%)$ and $31 \%$ in hospital], and providing timely support and care to improve symptoms and wellbeing for palliative patients (and their carers) with end-stage heart failure ( $82 \%$ of assessments report support from service had made a little/a lot of benefit and patients reported a significant improvement in quality of life $(\mathrm{P}<0.001,7$ point Likert scale) (12).

This qualitative study aimed to understand and explore the experiences of patients and carers of patients that were enrolled into the above pilot intervention, to better understand the impact and value of different components of the service. We present the following article in accordance with the COREQ reporting checklist (available at https:// dx.doi.org/10.21037/apm-21-709) (13).

\section{Methods}

\section{Study design and sample}

We performed a single-centre, qualitative study using focus groups. Participants were either adult patients or the bereaved carers of patients who had been enrolled in the Heart Failure Pilot Study. Written consent was obtained from each focus group participant for their interview to be recorded, transcribed and for the findings to be shared through presentations and publications.

The study conforms with the principles outlined in the Declaration of Helsinki (as revised in 2013) (14). This work was part of a board-approved Quality Improvement Project, approved by the St. Christopher's Hospice Research and Ethics Committee.

\section{Qualitative interviews}

The principal investigators (FH/JR) developed a topic guide (Appendix 1) to semi-structure the focus group discussions. Questions were open-ended and intended to facilitate the respondents to talk about aspects of care in their own words.

Three months after completion of the pilot intervention study, FH used convenience sampling to approach 21 out of 43 patients from the pilot by telephone. The 22 patients excluded were bedbound, housebound or suffered from 
dementia. Convenience sampling allowed us to offer each pilot study participant the opportunity to participate in a focus group, and out of the 21 approached, four patients agreed to attend. Others declined as one was in the inpatient unit, one was in hospital, others had appointments on the day, transport issues, had moved out of the area or didn't want to participate.

Forty-two patients enrolled in the pilot intervention had died, of which 29 relatives could be approached (13 had no surviving relative capable of undertaking a focus group or the relative had never been met by the service). Of the 29 relatives contacted, eight agreed to attend-however on the day, two were unwell and one had an unwell family member, leaving four attending the carers group and one attending as interpreter with his father.

Three focus groups took place between $14^{\text {th }}$ December 2018 and $18^{\text {th }}$ January 2019 , facilitated by colleagues not directly involved in the pilot study and who had no prior relationship with the participants. The participants were aware of the investigators' professions and interests in the project.

Two carer groups $(\mathrm{n}=2, \mathrm{n}=2)$ facilitated by AG (male spiritual care lead, and service user feedback lead) and CD (male specialty doctor) and one patient group $(n=4)$ facilitated by JL (female quality improvement lead) and RC (female trainee registrar) took place on hospice premises in a private room. The doctors had knowledge of qualitative research but had not been directly involved in previous research projects. AG and JL are both experienced in conducting qualitative interviews and with methods of service-user feedback.

All participants provided written informed consent prior to their focus group. All interviews were audio-recorded in English and in full and transcribed verbatim for later analysis. Participants were reminded that the transcripts would be checked for accuracy against the audio files, and any identifiable information would be redacted. They were also informed that their participation was entirely voluntary, and they were free to skip questions or leave the discussion at any point. Focus groups lasted on average an hour and were each completed in one session each.

\section{Coding and statistical analysis}

The initial thematic analysis was performed using NVivo version 10 software (QSR International UK Ltd., Warrington, UK). Data saturation was not reached due to the small number of participants. Transcripts were read, re- read and then coded independently and inductively by two of the co-authors (JR and RC, sense-checked by HR), the aim being to identify and categorise the different themes occurring in a cross-sectional manner across all interviews, (i.e., topics common to several individuals).

The process involved inductively analysing the data in relation to the following areas:

* The experience of being diagnosed with heart failure and living with the condition;

* Being referred to palliative care;

* What was deemed helpful in terms of care during the pilot;

* What was deemed unhelpful in terms of care during the pilot.

Overarching themes were identified and agreed upon by all authors through discussion and consensus.

\section{Results}

There were two to five participants per focus group (Table 1). Within the groups, there were four bereaved carers, all of whom were female consisting of three spouses and one daughter, who had cared for three men and one lady aged between 70 to 96 years. Two of these patients died at home, and two died in the hospice, and were under the service for 2 weeks, and 3, 7 and 14 months. There were four patient views, one of whom was represented by her son, and one who was accompanied by his son to assist with translation. Patients were aged between 70 to 87 years, were equally split female to male, and had been under the service for between 10 to 15 months.

Responses were mapped into four key areas: the experience of being diagnosed with heart failure and living with the condition, perceptions of referral to palliative care, key components of the new service that were deemed helpful, and lastly unhelpful in terms of care. Within these four areas, themes emerged including multimorbidity and understanding of heart failure and its trajectory, communication around referral to palliative care, having a 'broker' for the system, recognition of carer's needs, responsiveness of the service, and feeling 'in control'.

\section{The experience of being diagnosed with beart failure and living with the condition}

The first major theme to emerge from the groups was that heart failure was just one of many co-existing medical conditions. The patients often had multiple comorbidities, 
Table 1 demographic information of patients represented by the focus groups

\begin{tabular}{|c|c|c|c|c|c|c|c|c|c|}
\hline Identifier & Age & Gender & Length of care & AKPS & Lives with & Main carer & PPC & PPD & Place of death \\
\hline CAR02 & 79 & $M$ & 13 & 50 & Spouse & Spouse & Home & Hospice & Home \\
\hline CAR03 & 70 & M & 205 & 60 & Spouse & Spouse & Home & Hospice & Hospice \\
\hline CAR04 & 81 & $M$ & 104 & 60 & Spouse & Spouse & Home & Home & Hospice \\
\hline PAT02 & 80 & $M$ & 466 & 70 & Alone & Brother & Home & Undecided & N/A \\
\hline PAT03 & 77 & M & 483 & 60 & Spouse & Son & Home & Home & N/A \\
\hline PAT04 & 80 & $\mathrm{~F}$ & 308 & 40 & Family & Son & Home & Home & N/A \\
\hline
\end{tabular}

The data corresponds to the patient in each example, not the carer. AKPS, Australia-modified Karnofsky Performance Status; PPC, preferred place of care; PPD, preferred place of death.

were in and out of acute hospital, or had acute problems that precipitated a diagnosis of heart failure.

"My mum had a fall and broke ber hip and leg and was in [hospital]... and then she never really recovered and could only do a little bit of walking, and after that her heart failure was diagnosed and she was in and out of [hospital] a couple of times...." (CAR01)

"It started off because his kidneys bad started to pack up... he was put onto dialysis in ITU, then moved to a main ward..." (CAR02)

As a result of these multi-morbid and often complex medical conditions and a lack of continuity between primary care and each new hospital admission, people often didn't understand their condition, what drugs they were taking and why, and weren't sure how to navigate the system.

"I never understood heart failure as such because if your heart fails you die, right, so, what exactly is heart failure?" (PAT01)

"I wanted to discuss concerns with my GP-'can you tell me about the medication I take; there was so much of $i t$, I know what it's for, but I don't know I need it all' so my GP said to me 'I can't belp you; we don't actually advise what to take and what not to take, we just monitor you.' So where do I go then?" (PAT01)

\section{Being referred to palliative care}

Another major theme was around referral and particularly the way that palliative care was introduced. All participants to the pilot study should have been consented for referral to the service. What emerged from the focus group discussions was that people were initially afraid when palliative care was mentioned and felt that it was associated with end-of-life and dying.
"The GP asked me if I would like to have a consult (from the hospice). I told her yes... but I thought it was end-of-life... so it was a bit scary." (PAT03)

"It's actually not, I now know. That impression should not be there." (PAT04)

This feeling was echoed by others.

"Silly really, but I mean well like when you first heard the word palliative care, I also got a bit concerned." (PAT01)

"...We were told we were meeting the palliative care people and that started ringing bells with me." (CAR02)

Others were uncertain about how they became put in touch with the hospice service and didn't realise that it was associated with heart failure care. This links to a limited understanding of heart failure and its associated prognosis.

"I didn't know anything until [she] turned up on my doorstep and said I'm a palliative care nurse and I thought 'ob dear, do you know something I don't?"” (PAT02)

\section{What was deemed belpful in terms of care}

Table 2 below shows quotes from the study data that support the different key components of the integrated service that patients and/or carers deemed most helpful in terms of care.

For both patients and carers, improved understanding of their condition and planning for the future was important. In addition, a shared understanding with subsequent shared decision-making between patient, carer and different healthcare professionals was key. This led to patient wishes around advance care planning being explored, communicated and ultimately implemented as increasingly care and support moved from the hospital to community setting. 
Table 2 Quotes that support the different key components of the service that were most helpful for care

\begin{tabular}{|c|c|c|c|c|}
\hline Theme & Sub-theme 1 & Sub-theme 2 & Sub-theme 3 & Reflective quote \\
\hline \multirow[t]{5}{*}{$\begin{array}{l}\text { Future } \\
\text { understanding }\end{array}$} & $\begin{array}{l}\text { Shared decision } \\
\text { making and } \\
\text { understanding }\end{array}$ & $\begin{array}{l}\text { Cardiology and } \\
\text { palliative care team }\end{array}$ & - & $\begin{array}{l}\text { Yes, I knew it wouldn't be long because that's what [the consultant cardiologist] said when he introduced me to the ANP when we had his last appointment, that's when, I don't think (he) realised at the time, but I did, that his heart } \\
\text { was beginning to fail (CAR03) }\end{array}$ \\
\hline & \multirow[t]{2}{*}{$\begin{array}{l}\text { Advance care } \\
\text { planning }\end{array}$} & \multirow{2}{*}{$\begin{array}{l}\text { Wishes around } \\
\text { ceilings of treatment } \\
\text { and escalation }\end{array}$} & - & $\begin{array}{l}\text { She wanted to stay at home and that was all recorded, the ANP did all the guidance for that about mum staying at home and contacting the ambulance service because mum didn't want to go to hospital again, she was quite } \\
\text { adamant that she wasn't going to hospital (CAR01) }\end{array}$ \\
\hline & & & & $\begin{array}{l}\text { Anyway, there was someone at the (hospital), I think she was called ..., and we were introduced to her and she said there were three options, there was hospital, home and hospice and that's when we realised that this wasn't too } \\
\text { good, anyway, (he) always said home (CARO2) }\end{array}$ \\
\hline & \multirow[t]{2}{*}{ PPOC } & \multirow{2}{*}{$\begin{array}{l}\text { Being seen at home } \\
\text { rather than having } \\
\text { to attend hospital }\end{array}$} & - & So the ANP just came in 1 day and said that l've come about the heart failure and explained who she was and that we could have this at home instead of having to go to the (hospital) for check-ups and medication (CAR01) \\
\hline & & & & I think it would have been quite traumatic to have to take her to hospital for appointments (CAR01) \\
\hline \multirow[t]{15}{*}{$\begin{array}{l}\text { Broker for the } \\
\text { system }\end{array}$} & \multirow[t]{5}{*}{ Communication } & $\begin{array}{l}\text { Hospital } \\
\text { appointment }\end{array}$ & - & She was there at the cardiologist appointment as well. So, it's a mixture of support and there are things that you don't know so it is someone to ask...(PAT03) \\
\hline & & \multirow{2}{*}{$\begin{array}{l}\text { CMC-pan-London } \\
\text { electronic record } \\
\text { system }\end{array}$} & \multirow{2}{*}{$\begin{array}{l}\text { Knowledge of } \\
\text { 'their story' }\end{array}$} & The ANP explained "they already have your records, so you don't have to explain everything to the ambulance crew and all that" so we knew if we called that number...(PATO3) \\
\hline & & & & $\begin{array}{l}\text { That was recorded with the doctor and the ambulance service were informed as well, and in fact we did have an ambulance come because of her heart, she got chest pains and they helped her at home and contacted (the hospice) } \\
\text { (CAR01) }\end{array}$ \\
\hline & & \multirow[t]{2}{*}{$\begin{array}{l}\text { Linking between } \\
\text { services }\end{array}$} & \multirow[t]{2}{*}{ - } & $\begin{array}{l}\text { She could see that I needed a bit of help with dealing with practical [issues], dealing with other people. She would take the load from me and she would do the phone calls - it was such a relief (CAR04) } \\
\text { It pulled everything together (CAR04) }\end{array}$ \\
\hline & & & & Talk about interaction, the other thing l like about this service is that there is contact with the GP (PATO2) \\
\hline & \multirow{5}{*}{ Personalised } & \multirow{5}{*}{$\begin{array}{l}\text { Care around the } \\
\text { clock }\end{array}$} & \multirow{3}{*}{$\begin{array}{l}\mathrm{OOH} \text { response } \\
\text { and night visits }\end{array}$} & In the night-time, when you can't get through to a GP, you don't necessarily want an ambulance you would query as to whether it was the right thing ...(CAR01) \\
\hline & & & & I had to call them two nights, once they came from (the hospice), they had to get a cab to see him and the next night District Nurses and then, we did have a senior person came to talk about (his) future (CAR02) \\
\hline & & & & It was as though someone was always there (CAR03) \\
\hline & & & SPOC & $\begin{array}{l}\text { I knew that I could always phone, that was the biggest thing that you could phone } 24 \text { hours a day, even on bank holidays. They would have a record of all my calls... it was absolutely marvellous, and you spoke to someone who } \\
\text { knew who you were (CAR01) }\end{array}$ \\
\hline & & & & I remember thinking that this was marvellous because I had the phone card and the ANP said I could phone anytime to (the hospice) if there were any problems (CAR01) \\
\hline & \multirow{5}{*}{$\begin{array}{l}\text { Practical } \\
\text { support }\end{array}$} & What eligible for & - & The ANP helped her a lot with benefits 1 day, one thing she was getting DLA or something, not getting that much so she applied again, and she is getting more now (PAT04) \\
\hline & & Benefits & - & $\begin{array}{l}\text { I just applied for a blue badge, and I was going on holiday the next day, and I was supposed to go that day to the Civic Centre, I had been told about that at the Civic Centre where they make you run up and down the corridor and } \\
\text { say "you're ok". Go away.... Well, and they phoned me up and said you don't need to come, your badge is approved, and I thought that's the ANP's] done that. And the other thing was she said you get an attendance allowance, I } \\
\text { live on my own, and she said you're entitled to it, she said here you are, I'll fill in the form. It's worth quite a lot of money actually, I had that practical help very much and I'm very much appreciative of it (PAT02) }\end{array}$ \\
\hline & & Equipment & & One thing about also [the ANP] arranged a bed ... is very helpful you know; it goes up and down and adjusts (PAT04) \\
\hline & & Care package & & It was amazing and we had three times a day, (personal) care, who were amazing, can't fault them at all (CAR02) \\
\hline & & $\begin{array}{l}\text { Other healthcare } \\
\text { professionals }\end{array}$ & & (She) said well, I'll suggest it to your GP, which I think is the good thing about this is the linkup between (the hospice) and the GP and the surgery which is good (PAT02) \\
\hline
\end{tabular}

Table 2 (continued) 
Table 2 (continued)

Theme Sub-thent $\quad$ Om netsed
Sub-theme Sub-theme 2 Sub-theme 3 Reflective quote recognised

Sub-themes

Yes, they said to me we're not only here for (him) we're here for you (CARO2)

The ANP always asked how I was, and I would be able to say to her, it was a relationship that you could speak freely (CAR01)

There was always [the ANP] on hand that if you need help, you're to contact us, would you like someone to come and see him and you go off where you'd would like to, I had all that, help if need be, but I didn't take it up because I was able to be with him (CAROS)

Flexibility $\quad$ Our expertise $\quad$ Feeling safe

(E) sause this is what she said, she used to say not in a funny way or any way, it's not just about (him), it's also about you. You know, you need that strength and I did (CAR03)

She would phone me and say any problems, should I come around or should I leave it this week? (CAR01)

It gave you a sense that you're not alone (CARO3)

Her experience, number one was priority, she knew heart failure, and what it involved, that's what I found (CAR03)

You feel you could hand the burden onto someone else which was wonderful after 8 or 9 years (CARO4)

When [the ANP's] been dealing with me, it's for me, she was dealing with me, not like in a doctor's surgery, oh you might see that doctor once a week, or l've not got an appointment for 2 weeks, but I think with the ANP it became personal (CARO3)

Alongside expert Need for control I thought goodness me, I'm caring for you all the time and he would ask, when's that lady coming, when's the ANP coming, and I would say well I don't know, she can only come when she's not busy to come in and see how you carer $\quad$ are (CARO3)

Well, it was just that I was quite good at coping, I was a carer prior to (him) so I had that knowledge of being a carer, I had already nursed my elderly neighbour anyway with dementia, so I was aware of certain things (CAR03) ANP, advanced nurse practitioner; PPOC, preferred place of care; CMC, coordinate my care; GP, general practitioner; OOH, out of hours; SPOC, single point of contact; DLA, disability living allowance. 
One key benefit of the pilot was the sense that the advanced nurse practitioner was a broker for them in a complex health and social care system, including her being present across hospital and community settings and communicating on their behalf between professionals. Personalised care was embodied by a sense of 'being known' and being able to access advice around the clock. As health and function deteriorated, patients and carers appreciated timely access to practical support which was made possible by having a keyworker with both cardiac and palliative care expertise.

For carers, space and time for their own needs to be recognised and explored, alongside recognition of their experience, often over many years, was clearly valued. As the situation changed, a dovetailing of professional expertise with their own expertise enabled them to 'feel safe' and share the burden of care whilst still maintaining a sense of control.

\section{What was deemed unhelpful in terms of care}

There were of course some areas that could be improved upon, and experiences that patients or their carers felt were unhelpful, in respects to the service.

One of the common issues was around communication, and specifically response time to less urgent issues. A number of people reported frustration at either not being able to speak to the person they wanted, or not having calls returned. This is one of the pitfalls of a 24/7 service and although systems are in place to alert personnel to messages, it is not fool proof. There are of course times when a specific individual is unavailable and service users sometimes fail to understand that their issues could be addressed by another team-member. There may also have been instances where the service was under-resourced, particularly out-ofhours.

"Well first of all I rang [the ANP] and she was off or otherwise engaged and then ... I got to a point where I couldn't make it and then I tried to get hold of them, and I just couldn't get hold of them. So it is difficult to try and make contact." (PAT01)

"Sometimes it's hard to get through so I call and nobody's there and I leave a message for her but you don't get any call back from them so..." (PAT03)

"And twice I rang and twice she wasn't even told of the call I made." (PAT01)

A more positive criticism perhaps was that they felt referral to the service came too late, and they would have benefited from having more time in the programme. This is perhaps due to both healthcare professionals and patients and carers lacking recognition and understanding of deterioration in heart failure.

"He was only home for 3 [weeks]... we only had the short time... they were amazing the last 3 days and also for after care for me." (CAR02)

One of the most poignant and perhaps important reflections to come out of the focus group concerned a carer, who felt that her control was taken away right at the end of the patient's life.

"One of the nurses...she said we have put a catheter on (bim)... and we've had to sedate him three times. That threw me because she said he was getting agitated, but I wish now...I wish I'd been up there because I think he was getting anxious because be thought he wanted to go to the loo and not realising they'd done a catheter on him. I say they sedated him. She came and told me she'd done it. I wish they came and told me when she was going to do it before, because I kissed bim...(tearful)... but he didn't know it was me." (CAR03)

"It had quite an impact on me had they come down I think I'd have gone up to the bedroom and I started to blame myself, why did I come down and leave the nurses, I just thought I'd let them get on I just, where I used to get upset if I could see him getting upset, I thought I'll come down in case I make a fool of myself and get upset and then he'd go what's wrong with you, so I came down, but had the nurse or someone had come down and said he's getting a bit anxious and we feel we must sedate him, I think I might have gone up and I'm thinking that I might have said, you're ok, without sedation ... yes I'm bere and don't worry" (CAR03)

The same carer also reflected on her personal struggle that the patient recognised the service as being a help but not all of the support she had been giving. This demonstrates the importance of working alongside expert carers, and not taking away their control.

"I thought goodness me, I'm caring for you all the time and be would ask, when's that lady coming." (CAR03)

\section{Discussion}

The pilot intervention demonstrated that the majority of patients with end-stage heart failure were keen to avoid hospital admission, but required accessible, responsive, expert care in the community setting. Quantitative data from the pilot showed a reduction in hospital admissions and bed days (12). This qualitative study gives insight into what was important to patients and carers in achieving this.

With regards to the experience of being diagnosed and 
living with heart failure, evidence has shown that whilst most patients and carers are aware of their diagnosis, they have variable understanding of the seriousness or severity (11). This is in part due to the fluctuating trajectory of the disease (15). It can sometimes be difficult to connect that worsening symptoms indicate progression towards the end-of-life (11). Early and ongoing education is a valuable requirement of heart failure care, and can help bridge the gap between management of chronic disease and advance care planning.

This study supports current evidence that integrated working and early involvement of palliative services is an effective and cost-effective approach to care, yet there remains a significant mismatch in provision of these services, particularly in the community (16). Many successful trials, pilots and single-centre studies have demonstrated that a team-based approach, using qualities from a variety of disciplines that met regularly to discuss their patients, have significant benefits through reciprocal learning and education, prioritising of patient-centred treatment and streamlined communication across services (10,12,17-20). Empirical studies have shown that palliative care improves quality of life by reducing symptom burden, hospital admissions, and by addressing their needs, goals and wishes throughout the heart failure journey (10).

This study highlighted that triggers for referral into the service and how this is communicated to a patient is key. We know that professionals and patients have preconceived ideas of 'palliative care' and this in itself is a barrier to referral (15). Ongoing stigma of the word 'palliative' with an association of 'death', 'dying' and 'end-of-life' represents a significant barrier to integrative working $(16,21)$. Truly integrated services should welcome palliative care as part of the wider team.

We know that there are multiple barriers to communication and advance care planning in this population $(11,15,16,22-33)$, and that shared decisionmaking, communication between professionals (cardiology, primary care, community nursing and out-of-hours providers including ambulance services) is key to enabling the right care to be given at the right time in the right place. It is important that services continue to embed opportunities to discuss advance care planning with heart failure patients and their carers to establish what is important to them at their stage of life and illness and to align care plans to meet the patients' goals and values (11).

The availability of a community service wrapped around the patient and caregiver helped people feel safe and supported and to ensure that care and support increased appropriately with increasing need. Flexibility in service provision and continuity of care is a challenge when services are stretched, resources are finite and there is an everincreasing in-need population. A service is required that provides continuity of access to expert advice even when a specific keyworker is unavailable. Single point of contact and shared electronic records are key components that help ensure continuity of care (34).

Working alongside caregivers, facilitating a strengthsbased approach (maximising what they can do) and using their expertise to identify when deterioration occurs can direct finite resources in a more targeted way. It is important to recognise that caregivers are often best placed to identify nuances of change in the patient which may not be detected by the healthcare professionals themselves (34).

Evidence shows that caregivers have many unmet information needs $(11,24)$, particularly in the heart failure population due to its fluctuating trajectory $(16,33)$. The unpredictability of chronic illnesses means that carers have to constantly adjust their role, and this in turn can impact on their 'self-identity' and relationship with the patient (34). It is important to recognise their vulnerability as well as their strengths. One of the carers in this study was profoundly affected by the well-meaning but unconsciously ignorant actions of healthcare professionals, whose aim was to control the patient's symptoms but in doing so prevented the carer from saying goodbye to her husband. It is important to not only educate staff on symptom management and communication skills, but also to teach 'emotional intelligence' skills. Recognition and positive reinforcement of the expert carers' strengths, whilst acknowledging and addressing their worries, fears and anxieties helps to encourage a positive 'sharedcare' relationship $(33,34)$. Allowing the carer to maintain 'emotional control' whilst offering support and knowledgeexchange to facilitate their role is important (35).

\section{Strengths and limitations}

This paper describes views from a small cohort of patients and carers after completion of the pilot study. Despite the use of convenience sampling, carers were representative of the whole cohort. Patients were self-selecting in terms of those who had lived longer, and sample bias is acknowledged as only those able to travel to the focus group were included. Despite these limitations, the sample achieved variations across all characteristics deemed to be 
important.

The time period between the participant's engagement in the pilot study and the focus group being conducted varied, and this may increase the risk of recall bias. One patient attended their focus group with their carer, which may have impacted the answers given.

The population of Bromley is an area of relative wealth, minimal cultural diversity, and predominantly consists of multi-morbid elderly people. How the findings of both the pilot and this qualitative study would hold among a more culturally diverse population is unknown. Different populations and cultures have different preferences around end-of-life care, and this may limit the transferability of the study findings. Bromley is also a relatively wellserved urban area, with a specialist palliative care team and local community healthcare teams. Other more rural or less densely populated geographical areas may have more limited access to these types of resources.

Reflecting on a painful experience such as terminal illness and death of a loved one can deter engagement, which may have affected participation. It is also acknowledged that those who participated were likely to have wanted to help the service in return for having had a positive experience in the pilot study. Focus group participants did not provide feedback on the findings of this qualitative study.

\section{Implications for clinical practice}

Although this is taken from a small local pilot, there are a number of important learning points to be drawn.

Firstly, understanding and acknowledging the difficulties of living with a chronic but changing condition, and the impact on the patient and carer; not just physically, but emotionally, psychologically, and on their social functioning, sense of identity, and relationship with each other over time.

Secondly, managing uncertainty in an uncertain trajectory involves healthcare professionals recognising that a patient is deteriorating and therefore engaging palliative care services early. It also requires educating the wider multidisciplinary team to discuss advance care planning earlier on in the disease trajectory. Educating patients and carers about heart failure itself is key, particularly recognising that it is an irreversible and terminal condition, punctuated by periods of acute illness, recovery and stability, and how to manage the changing demands each of these periods entails.

Developing the emotional intelligence skills of healthcare professionals is important and in particular learning how to work alongside carers to empower them and maintain their sense of control, rather than 'taking over' and 'problem solving'.

One of the most important findings is around continuity of care. The study has highlighted the value of a responsive service offering continuity, and a space to talk, not only about advance care planning, but about what is important to individuals, to create a truly personal service which upholds patient values. It is becoming increasingly difficult to ensure continuity even within a single organisation because of the piecemeal way that health and social care is organised.

\section{Implications for research}

It is important, as with all clinical services from an audit and governance perspective, that new services continually evaluate benefit and evolve.

More attention needs to be given to the caregiver's mental, physical and psychological health needs through longitudinal assessment, to assess change over time, particularly in chronic and fluctuating illnesses.

There needs to be ongoing development of selfmanagement interventions for patients and carers to help empower them in their own care, and to facilitate focussing resources on where they are most needed in an everincreasing population with growing palliative care needs.

Ongoing research is needed into the optimal timing and integration of palliative care into heart failure management, and analysis of the long-term outcomes of early palliative care.

\section{Conclusions}

This study identifies important considerations when developing an integrated heart failure and palliative care service. Results should be considered within the context of the existing literature which suggests that integrated working and early involvement of palliative care in the patient (and carer) journey is both effective and costeffective. We propose that there be an increased focus on education about heart failure and its trajectory, involving not only patients and carers, but also the multidisciplinary team to promote shared learning and facilitate open communication for better patient-centred care. This study also contributes to the evidence that communication around palliative care, death and dying remains poor, which can create barriers to future discussions about advance care planning. We also suggest that more focus be centred on 
the 'expert-carer' whom our study has highlighted can often feel overlooked both by the patient and the service that is supposed to be supporting them. Future studies should continue to focus on early palliative care in heart failure and other chronic terminal diseases, and integration of services, particularly community resources. The results of this study highlight the importance of joined-up care or a single point of contact for patients and carers, so that they feel 'known' and 'safe' through the relationship they are able to build with the service.

\section{Acknowledgments}

The authors would like to thank the participants who took part in the focus groups and would like to acknowledge Jean Levy and Andrew Goodhead for their support in conducting the interviews. The abstract from this study has been accepted for poster presentation at the Association of Palliative Medicine's Palliative Care Congress, March 2021.

Funding: None.

\section{Footnote}

Reporting Checklist: The authors have completed the COREQ reporting checklist. Available at https://dx.doi. org/10.21037/apm-21-709

Data Sharing Statement: Available at https://dx.doi. org/10.21037/apm-21-709

Peer Review File: Available at https://dx.doi.org/10.21037/ apm-21-709

Conflicts of Interest: All authors have completed the ICMJE uniform disclosure form (available at https://dx.doi. org/10.21037/apm-21-709). The authors have no conflicts of interest to declare.

Ethical Statement: The authors are accountable for all aspects of the work in ensuring that questions related to the accuracy or integrity of any part of the work are appropriately investigated and resolved. The study was conducted in accordance with the Declaration of Helsinki (as revised in 2013). The study was approved by the St. Christopher's Hospice Research and Ethics Committee and written informed consent was taken from all individual participants.
Open Access Statement: This is an Open Access article distributed in accordance with the Creative Commons Attribution-NonCommercial-NoDerivs 4.0 International License (CC BY-NC-ND 4.0), which permits the noncommercial replication and distribution of the article with the strict proviso that no changes or edits are made and the original work is properly cited (including links to both the formal publication through the relevant DOI and the license). See: https://creativecommons.org/licenses/by-nc-nd/4.0/.

\section{References}

1. NICE guideline [NG106]. Chronic Heart Failure in adults: diagnosis and management. 2018. Available online: https://www.nice.org.uk/guidance/ng106

2. Connolly M, Beattie J, Walker D, et al. End of life care in heart failure: a framework for implementation. 2014. Available online: https://www.england.nhs.uk/ improvement-hub/publication/end-of-life-care-in-heartfailure-a-framework-for-implementation/

3. Nicholson C, Davies JM, George R, et al. What are the main palliative care symptoms and concerns of older people with multimorbidity?-a comparative cross-sectional study using routinely collected Phase of Illness, Australiamodified Karnofsky Performance Status and Integrated Palliative Care Outcome Scale data. Ann Palliat Med 2018;7:S164-75.

4. McIlvennan CK, Allen LA. Palliative care in patients with heart failure. BMJ 2016;353:11010.

5. World Health Organisation. Palliative care. 2012. Available online: https://www.who.int/cancer/palliative/definition/ en/ (Accessed January, 2020).

6. Ponikowski P, Voors AA, Anker SD, et al. 2016 ESC Guidelines for the diagnosis and treatment of acute and chronic heart failure: The Task Force for the diagnosis and treatment of acute and chronic heart failure of the European Society of Cardiology (ESC). Developed with the special contribution of the Heart Failure Association (HFA) of the ESC. Eur J Heart Fail 2016;18:891-975.

7. Jaarsma T, Beattie JM, Ryder M, et al. Palliative care in heart failure: a position statement from the palliative care workshop of the Heart Failure Association of the European Society of Cardiology. Eur J Heart Fail 2009;11:433-43.

8. Kavalieratos D, Corbelli J, Zhang D, et al. Association between palliative care and patient and caregiver outcomes: a systematic review and meta-analysis. JAMA 2016;316:2104-14.

9. Ecarnot F, Meunier-Beillard N, Seronde MF, et al. End- 
of-life situations in cardiology: a qualitative study of physicians' and nurses' experience in a large university hospital. BMC Palliat Care 2018;17:112.

10. Brännström M, Boman K. Effects of person-centred and integrated chronic heart failure and palliative home care. PREFER: a randomized controlled study. Eur J Heart Fail 2014;16:1142-51.

11. Im J, Mak S, Upshur R, et al. 'The Future is Probably Now': Understanding of illness, uncertainty and end-oflife discussions in older adults with heart failure and family caregivers. Health Expect 2019;22:1331-40.

12. Ross JR, Hodson F, Karwatowski S, et al. 18 Heart failure and palliative care: an integrated service for patients across hospital and community settings. BMJ Supportive \& Palliative Care 2019;9:A7.

13. Tong A, Sainsbury P, Craig J. Consolidated criteria for reporting qualitative research (COREQ): a 32-item checklist for interviews and focus groups. Int J Qual Health Care 2007;19:349-57.

14. Rickham PP. Human experimentation. code of ethics of the world medical association. Declaration of Helsinki. Br Med J 1964;2:177.

15. Selman L, Harding R, Beynon T, et al. Improving end-oflife care for patients with chronic heart failure: "Let's hope it'll get better, when I know in my heart of hearts it won' $t$ ". Heart 2007;93:963-7.

16. Chow J, Senderovich H. It's time to talk: challenges in providing integrated palliative care in advanced congestive heart failure. A narrative review. Curr Cardiol Rev 2018;14:128-37.

17. Aiken LS, Butner J, Lockhart CA, et al. Outcome evaluation of a randomized trial of the PhoenixCare intervention: program of case management and coordinated care for the seriously chronically ill. J Palliat Med 2006;9:111-26.

18. Bekelman DB, Hooker S, Nowels CT, et al. Feasibility and acceptability of a collaborative care intervention to improve symptoms and quality of life in chronic heart failure: mixed methods pilot trial. J Palliat Med 2014;17:145-51.

19. Mitchell G, Zhang J, Burridge L, et al. Case conferences between general practitioners and specialist teams to plan end of life care of people with end stage heart failure and lung disease: an exploratory pilot study. BMC Palliat Care 2014;13:24.

20. Wong FK, Ng AY, Lee PH, et al. Effects of a transitional palliative care model on patients with end-stage heart failure: a randomised controlled trial. Heart
2016;102:1100-8.

21. Siouta N, Clement P, Aertgeerts B, et al. Professionals' perceptions and current practices of integrated palliative care in chronic heart failure and chronic obstructive pulmonary disease: a qualitative study in Belgium. BMC Palliat Care 2018;17:103.

22. Butler J, Binney Z, Kalogeropoulos A, et al. Advance directives among hospitalized patients with heart failure. JACC Heart Fail 2015;3:112-21.

23. Ahluwalia SC, Levin JR, Lorenz KA, et al. Missed opportunities for advance care planning communication during outpatient clinic visits. J Gen Intern Med 2012;27:445-51.

24. Beernaert K, Deliens L, De Vleminck A, et al. Early identification of palliative care needs by family physicians: a qualitative study of barriers and facilitators from the perspective of family physicians, community nurses, and patients. Palliat Med 2014;28:480-90.

25. Browne S, Macdonald S, May CR, et al. Patient, carer and professional perspectives on barriers and facilitators to quality care in advanced heart failure. PLoS One 2014;9:e93288.

26. Hanratty B, Hibbert D, Mair F, et al. Doctors' perceptions of palliative care for heart failure: focus group study. BMJ 2002;325:581-5.

27. Kavalieratos D, Mitchell EM, Carey TS, et al. "Not the 'grim reaper service'": an assessment of provider knowledge, attitudes, and perceptions regarding palliative care referral barriers in heart failure. J Am Heart Assoc 2014;3:e000544.

28. Siouta N, van Beek K, Preston N, et al. Towards integration of palliative care in patients with chronic heart failure and chronic obstructive pulmonary disease: a systematic literature review of European guidelines and pathways. BMC Palliat Care 2016;15:18.

29. Arnold JM, Liu P, Demers C, et al. Canadian Cardiovascular Society consensus conference recommendations on heart failure 2006: diagnosis and management. Can J Cardiol 2006;22:23-45.

30. McClung JA. End-of-life care in the treatment of heart failure in the elderly. Clin Geriatr Med 2007;23:235-48.

31. Edmonds P, Karlsen S, Khan S, et al. A comparison of the palliative care needs of patients dying from chronic respiratory diseases and lung cancer. Palliat Med 2001;15:287-95.

32. Fendler TJ, Swetz KM, Allen LA. Team-based palliative and end-of-life care for heart failure. Heart Fail Clin 2015;11:479-98. 
33. Noonan MC, Wingham J, Taylor RS. 'Who Cares?' The experiences of caregivers of adults living with heart failure, chronic obstructive pulmonary disease and coronary artery disease: a mixed methods systematic review. BMJ Open 2018;8:e20927.

34. Alvariza A, Årestedt K, Boman K, et al. Family members' experiences of integrated palliative advanced home and

Cite this article as: Chester R, Richardson H, Doyle C, Hodson F, Ross JR. Heart failure-the experience of living with end-stage heart failure and accessing care across settings. Ann Palliat Med 2021;10(7):7416-7427. doi: 10.21037/apm-21-709 heart failure care: a qualitative study of the PREFER intervention. Palliat Support Care 2018;16:278-85.

35. Aasbø G, Solbraekke KN, Kristvik E, et al. Between disruption and continuity: challenges in maintaining the 'biographical we' when caring for a partner with a severe, chronic illness. Sociol Health Illn 2016;38:782-96. 


\section{Supplementary}

\section{Topic guide}

* What support did you receive as part of the pilot?

- Practical help?

- What sort of things were most useful?

- Emotional support?

- Information

- About what?

- How was this given?

- Verbal/written

- Did you have opportunity to express your wishes and concerns

- Were these respected/met?

- What was missing? What else would have been useful?

* What support did your family/carer receive as part of the pilot?

- Practical help?

- What sort of things were most useful?

- Emotional support?

- Information sharing?

- About what?

- How was this given?

- Verbal/written

- What was missing? What else would have been useful?

* Did the pilot have any impact on your engagement with

- GP

- Princes Royal Hospital Heart Failure Team

- Number(s) of appointments you needed to attend

* We hoped that this service would 'join up' and streamline communication. Can you give any examples where this helped in your situation?

* Out of hours can be a very stressful time

- Were you able to access help when you needed to - can you give examples

- Was this a timely response?

- Did you get the help you were seeking?

* Is there anything else that you would like to tell us?

- Either about what went well?

- Or about what didn't go so well? 